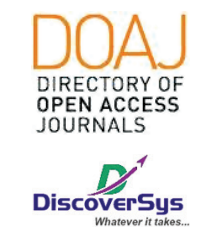

Published by DiscoverSys

\section{Factors associated with unfavourable outcome after Burr Hole drainage in Subdural Hematoma (SDH) at Sanglah General Hospital, Bali, Indonesia}

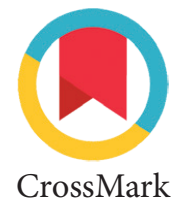

\author{
I Gusti Ngurah Purnomo, ${ }^{1 *}$ I Wayan Niryana, ${ }^{2}$ Nyoman Golden ${ }^{2}$
}

\title{
ABSTRACT
}

Background: Subdural hematoma is a neurosurgical disorder that often occurs in the elderly with simple, relatively fast and minimally invasive surgical therapy, but has a high postoperative mortality rate due to unfavourable outcome. This study aims to evaluate factors associated with unfavourable outcome after burr hole drainage in a subdural hematoma (SDH) at Sanglah General Hospital, Bali, Indonesia.

Method: A prospective cohort study was conducted among 60 respondents to determine factors influencing the outcome of patients with subdural hematoma after burr hole drainage. The independent variables in this study included age, comorbid factors, trauma onset, GCS, hematoma thickness, and midline shift. Dependent variables include the Glasgow Outcome Scale (GOS), which is divided into 2 groups, favourable outcome, and unfavourable outcome. Data were analyzed using SPSS version 17 for Windows.

Results: There were 19 respondents (31.7\%) had unfavourable outcomes and 41 respondents (68.3\%) had favourable outcomes. From the bivariate analysis, significant associated risk factors were found in the onset of trauma $(p=0.048), \mathrm{GCS}(p=0.000)$, hematoma thickness $(p=0.000)$, and midline shift $(p=0.000)$. From the multivariate analysis, it was found that low GCS was the most dominant risk factor for the unfavourable outcome following burr hole drainage $(O R=22.30$; $95 \% \mathrm{Cl}=2.22-223.80 ; \mathrm{p}=0.008)$

Conclusion: This study concludes that low GCS was the most dominant risk factor for unfavourable outcome in patients with subdural hematoma after burr hole drainage
${ }^{1}$ General Surgery Resident, Department of Surgery, Faculty of Medicine, Universitas Udayana, Sanglah General Hospital, Bali, Indonesia

${ }^{2}$ Division of Neurosurgery, Department of Surgery, Faculty of Medicine, Universitas Udayana, Sanglah General Hospital, Bali, Indonesia
${ }^{*}$ Correspondence to:

I Gusti Ngurah Purnomo; General Surgery Resident, Department of Surgery, Faculty of Medicine, Universitas Udayana, Sanglah General Hospital, Bali, Indonesia ngurahpurnomonc9@gmail.com

Received: 2020-03-11 Accepted: 2020-06-20 Published: 2020-07-19

Keywords: Subdural Hematoma, Burr hole drainage, Unfavorable Outcome

Cite This Article: Purnomo, I.G.N., Niryana, I.W., Golden, N. 2020. Factors associated with unfavourable outcome after Burr Hole drainage in Subdural Hematoma (SDH) at Sanglah General Hospital, Bali, Indonesia. Intisari Sains Medis 11(2): 561-565. D0I: 10.15562/ism.v11i2.731

\section{INTRODUCTION}

Subdural Hematoma (SDH) is a disorder that is quite often faced in the field of neurosurgery, and the majority occur in old age. ${ }^{1}$ In general, based on the onset, subdural hematomas are classified into the acute phase (less than 3 days), the subacute phase (between 4 to 21 days), and the chronic phase (lasting more than 21 days). ${ }^{2}$

Based on a previous study conducted by David Balser et al. in 2015, the incidence of chronic SDH has continued to increase since 1967 in the global population. ${ }^{3}$ At present, the annual incidence rate has reached 20 cases per 100,000 people in America which is predicted that in 2030 around 60,000 Americans will suffer from chronic SDH every year. ${ }^{3,4}$

More than $20 \%$ of chronic SDH patients have poor neurological outcomes and produce significant disabilities. ${ }^{5}$ Surgical treatment in patients with subacute and chronic SDH is quite merely with relatively fast and minimally invasive surgery times. ${ }^{5}$ The perioperative mortality rate for patients with chronic SDH ranges from $1.2 \%$ to $11 \%$. While elderly patients who undergo post-burr-hole drainage treatment, have a $32 \%$ mortality rate in the first year. ${ }^{4-6}$

SDH that occurs in old age is associated with a reduction in brain volume and an increase in the area of the subdural cavity. ${ }^{7,8}$ This will cause stretching of bridging veins and are prone to trauma, even minor injury (trivial trauma). ${ }^{8}$ Besides age and trauma factors, a history of chronic diseases such as diabetes mellitus (DM) and hypertension, as well as a history of coagulopathy, such as a history of using anticoagulant therapy or antiplatelet therapy or thrombolytic therapy, and haematological disorders with an increased risk of bleeding, hepatic failure, or a history of hemodialysis can also trigger $\mathrm{SDH} .{ }^{9,10}$ Besides, neurological conditions and pre-operative CT scan images were also associated with patient outcomes after burr hole drainage. ${ }^{11,12}$

Based on those mentioned above, this study aims to evaluate various factors related to unfavourable outcomes in patients with SDH after undergoing burr hole drainage therapy at Sanglah General Hospital, Bali, Indonesia. 


\section{METHODS}

A prospective cohort study was conducted from among 60 respondents during January 2017-September 2018 at Sanglah General Hospital, Bali. The independent variables in this study were age, comorbid factors, trauma onset, GCS, hematoma thickness, and midline shift following burr hole drainage. In comparison, the dependent variable is the Glasgow Outcome Scale (GOS) which examined at the time over 3 months postoperatively by conducting patient interviews at the clinic or by telephone.

Based on age, they were divided into 2 groups, namely $<60$ years of age and $>60$ years. The comorbid factors evaluated were diabetes mellitus, hypertension and coagulopathy, which were divided into two groups, namely present or not. The onset of trauma was divided into 2 groups, namely less than or equal to 21 days and more than 21 days. GCS is divided into 2 groups, namely GCS less than 13 and more or equal to 13. Measurement of hematoma thickness from the results of CT scan of the head, which is divided into 2 groups, namely

\section{Tabel 1 Baseline characteristic of respondents}

\begin{tabular}{|c|c|}
\hline Variables & Respondents $(n=60)$ \\
\hline \multicolumn{2}{|l|}{ Age, n (\%) } \\
\hline$>60$ years & $41(68.3)$ \\
\hline$\leq 60$ years & $19(31.7)$ \\
\hline \multicolumn{2}{|l|}{ Gender, n (\%) } \\
\hline Male & $47(78.3)$ \\
\hline Female & $13(21.7)$ \\
\hline \multicolumn{2}{|c|}{ Comorbid factors, $\mathbf{n}(\%)$} \\
\hline Yes & $37(61.7)$ \\
\hline No & $23(38.3)$ \\
\hline \multicolumn{2}{|c|}{ Onset of Trauma, $\mathbf{n}(\%)$} \\
\hline$>21$ days & $27(45.0)$ \\
\hline$\leq 21$ days & $33(55.0)$ \\
\hline \multicolumn{2}{|c|}{ Glasgow Coma Scale (GCS), n (\%) } \\
\hline$>13$ & $32(53.3)$ \\
\hline$<13$ & $28(46.7)$ \\
\hline \multicolumn{2}{|c|}{ Thickness of Hematome, $\mathbf{n}(\%)$} \\
\hline$>15 \mathrm{~mm}$ & $27(45.0)$ \\
\hline$<15 \mathrm{~mm}$ & $33(55.0)$ \\
\hline \multicolumn{2}{|c|}{ Midline shift, n (\%) } \\
\hline$>10 \mathrm{~mm}$ & $20(33.3)$ \\
\hline$<10 \mathrm{~mm}$ & $40(66.7)$ \\
\hline \multicolumn{2}{|c|}{ The outcome, $n(\%)$} \\
\hline Unfavourable & $19(31.7)$ \\
\hline Favourable & $41(68.3)$ \\
\hline
\end{tabular}

the thickness of the hematoma is less or equal to $15 \mathrm{~mm}$ or more than $15 \mathrm{~mm}$. Midline Shift is the midline shift on the head CT scan, which is divided into 2 groups, which are less than or equal to $10 \mathrm{~mm}$ and more than $10 \mathrm{~mm}$.

The outcome was assessed 3 months postoperatively using the Glasgow Outcome Scale (GOS). It was divided into 2 groups, namely favourable outcomes, consisting of maximum recovery, moderate disability, and severe disability. In contrast, the unfavourable outcome was consisting of vegetative persistence and death. Data were analyzed with SPSS software version 17 for Windows.

\section{RESULTS}

The characteristics of respondents can be depicted in Table 1. Most of the respondents were patients aged $>60$ years $(68.3 \%)$. In addition, based on several variables assessed in this study, most of respondents were male (78.3\%), having comorbidities $(61.7 \%)$, onset of trauma $\leq 21$ days $(55.0 \%)$, GCS score $>13$ (53.3\%), thickness of hematoma $<15 \mathrm{~mm}$ (55.0\%), midline shift < $10 \mathrm{~mm}$ (66.7\%), and favourable outcome (68.3\%) (Table 1).

In Table 2, there was no significant relationship between age $>60$ years $(\mathrm{p}=0.072)$ and the presence of comorbid factors $(\mathrm{p}=0.061)$ with unfavourable outcomes in SDH patients after burr hole drainage procedure $(p>0.05)$. However, the onset of trauma $\leq 21$ days has a significant relationship with the occurrence of unfavourable outcomes in $\mathrm{SDH}$ patients after burr hole drainage $(\mathrm{p}=0.048)$ (Table 2).

GCS variable less than 13 with unfavourable outcome were found in 18 respondents $(94.3 \%)$ and 10 respondents (24.4\%) with a favourable outcome. In comparison, GCS > 13 with unfavourable outcome were found in 1 respondent (5.3\%) and 31 respondents $(75.6 \%)$ with favourable outcome $(\mathrm{p}=0,000)$, indicating there was a significant relationship between GCS status and the occurrence of unfavourable outcomes in SDH patients after burr hole drainage (Table 2). Moreover, the thickness of hematome $>15$ millimetre and the midline shifts $>10$ millimetres have a significant relationship with the occurrence of unfavourable outcomes in $\mathrm{SDH}$ patients after burr hole drainage $(\mathrm{p}=0.000)$ (Table 2).

Table 3 shows that GCS status data is the most significant risk factor for the outcome of SDH patients after burr hole drainage (OR: 22.3; CI 95\%: 2.22-223.8; $\mathrm{p}=0.008)$. This means that there is an influence of GCS status $<13$ on the unfavourable outcome of SDH patients after burr hole drainage 22.3 times compared with the favourable outcome group by logistic regression test (Table 3 ). 
Table 2 The relationship between age, gender, comorbid factors, the onset of trauma, GCS Status, the thickness of hematoma, and midline shift with the outcome of SDH patients after burr hole drainage

\begin{tabular}{|c|c|c|c|c|c|}
\hline \multirow[b]{2}{*}{ Variable } & \multicolumn{2}{|c|}{ Outcome } & \multirow[b]{2}{*}{ IRR } & \multirow[b]{2}{*}{ ICI 95\% } & \multirow[b]{2}{*}{ Ip-value } \\
\hline & $\begin{array}{c}\text { Unfavorable } \\
\quad(n=19)\end{array}$ & $\begin{array}{c}\text { Favorable } \\
(n=41)\end{array}$ & & & \\
\hline \multicolumn{6}{|l|}{ Age, $n(\%)$} \\
\hline$>60$ years & $16(84,2)$ & $25(61.0)$ & 2.4 & $0.81-7.47$ & 0.072 \\
\hline$\leq 60$ years & $3(15,8)$ & $16(39.0)$ & & & \\
\hline \multicolumn{6}{|c|}{ Comorbid Factors, n (\%) } \\
\hline Yes & $15(78.9)$ & $22(53.7)$ & 2.3 & $0.88-6.16$ & 0.061 \\
\hline No & $4(21.1)$ & $19(46.3)$ & & & \\
\hline \multicolumn{6}{|c|}{ Onset of Trauma, n (\%) } \\
\hline$>21$ days & $5(26.3)$ & $22(53.7)$ & 0.43 & $0.18-1.05$ & 0.048 \\
\hline$\leq 21$ days & $14(73.7)$ & $19(46.3)$ & & & \\
\hline \multicolumn{6}{|c|}{ GCS score, n (\%) } \\
\hline$<13$ & $18(94.3)$ & $10(24.4)$ & 20.5 & 2.93-144.41 & 0.000 \\
\hline$>13$ & $1(5.3)$ & $31(75.6)$ & & & \\
\hline \multicolumn{6}{|c|}{ Thickness of hematoma, n (\%) } \\
\hline$>15 \mathrm{~mm}$ & $17(89.5)$ & $10(24.4)$ & 10.3 & $2.62-41.05$ & 0.000 \\
\hline$<15 \mathrm{~mm}$ & $2(10.5)$ & $31(75.6)$ & & & \\
\hline \multicolumn{6}{|c|}{ Midline shift, n (\%) } \\
\hline$>10 \mathrm{~mm}$ & $14(73.7)$ & $6(14.6)$ & 5.6 & $2.34-13.34$ & 0.000 \\
\hline$<10 \mathrm{~mm}$ & $5(26.3)$ & $35(85.4)$ & & & \\
\hline
\end{tabular}

Table 3 The effect onset of trauma, GCS score, the thickness of hematoma, and midline shift against the unfavourable outcome of SDH patients post burr hole drainage

\begin{tabular}{lcccccc}
\hline Variables & B & SE & $\boldsymbol{\beta}$ & Exp(B) & Cl 95\% & p-value \\
\hline The onset of trauma $>$ 21 days & -1.22 & 0.93 & 1.73 & 0.29 & $0.04-1.82$ & 0.188 \\
GCS $<13$ & 3.10 & 1.17 & 6.96 & 22.30 & $2.22-223.8$ & 0.008 \\
The thickness of hematome $>15 \mathrm{~mm}$ & 1.68 & 1.23 & 1.84 & 5.37 & $0.47-60.79$ & 0.174 \\
Midline shift $>10 \mathrm{~mm}$ & 1.32 & 1.10 & 1.43 & 3.772 & $0.42-33.17$ & 0.231 \\
\hline
\end{tabular}

\section{DISCUSSION}

From 60 respondents involved in this study, 19 respondents $(31.7 \%)$ had unfavourable outcomes and 41 respondents $(68.3 \%)$ favourable outcomes. Based on the analysis with Chi-Square it was found that the onset of trauma, GCS status, hematoma thickness, and midline shift had a significant relationship with the occurrence of unfavourable outcomes in SDH patients after burr hole drainage. After a logistic regression test, it was found that GCS was the most significant risk factor associated with outcomes in SDH patients after burr hole drainage.

Older post-burr hole drainage SDH patients tend to have worse outcomes in this study. ${ }^{13}$ This might be related to a large number of comorbidities such as increasing age, reduced brain recovery capacity, decreased blood vessel elasticity, and the occurrence of brain atrophy resulting in vessels dura blood which is more susceptible to damage after trauma. ${ }^{13,14}$ However, in this study, no significant relationship was found between age and the presence of comorbid factors with unfavourable outcomes in SDH patients after burr hole drainage. This finding is consistent with the previous study conducted by Kim DH et al., where age and history of comorbid factors are not significantly related to outcome. $^{15}$

In this study, there was a significant relationship of the trauma onset $<21$ days with the occurrence of unfavourable outcomes in SDH patients after burr hole drainage. This is similar to a previous study 
by Kim $\mathrm{DH}$ et al., and Kim DI et al., whereas a history of trauma is associated with poor outcomes at long-term follow-up. ${ }^{15,16}$ This might be occurred due to the patients with trauma onset $<21$ days had an active bleeding and blood clots that have not fully experienced a noticeable dilution. From the CT scan evaluation, there was a hyperdense image which difficult to drain with burr hole action. This is consistent with research conducted by Rovlias A et al., that high density and mixed hematomas on CT scans are associated with unfavourable outcomes, whereas according to Wang YQ et al., low densities are associated with increased neurological status and low incidence of recurrence. ${ }^{14,17}$

Hematome thickness of more than 15 millimetres and midline shift above $10 \mathrm{~mm}$ in this study have a significant relationship with the occurrence of unfavourable outcomes in SDH patients after burr hole drainage. The thickness of hematoma is related to the presence of brain atrophy, and the discovery of a midline shift indicates that there has been an urgency by a mass lesion on one side..$^{18} \mathrm{~A}$ similar result was found in the study conducted by Rovlias A et al., where the thickness of the hematoma was associated with poor outcomes and recurrence incidence in chronic SDH patients after burr hole drainage. ${ }^{14}$ Meanwhile, according to Wang YQ et al., and Kim DH et al., studies, midline shift was not related to outcomes in patients with $\mathrm{CSDH}$ post burr hole drainage. ${ }^{15,17}$ This is due to the role of midline shift in assessing prognosis must be related to other CT scan findings. In contrast, the degree of midline shift is also influenced by the location of the SDH and the presence of additional lesions.

After a logistic regression performed, it was found that GCS status was the most significant risk factor with the unfavourable outcomes in chronic SDH patients after burr hole drainage. This is consistent with previous studies conducted by Tae H.K et al. and Yasuaki A et al. that early GCS is associated with outcomes in chronic SDH patients after burr hole drainage. ${ }^{13,19}$ Decreased consciousness in chronic SDH patients is different from acute head trauma patients. In the acute head trauma, decreased consciousness is related to the severity of primary brain injury, whereas in chronic $\mathrm{SDH}$, decreased consciousness occurs due to chronic processes of non-traumatic factors. ${ }^{20}$

The limitation of this study is no differentiation of burr hole procedure, whether a single hole or twin holes might affect the outcome. Another study limitation is the Glasgow Outcome Scale (GOS) score was evaluated over 3 months, so the GOS of patients evaluated over 3 months may not be related to the burr hole was conducted, but might be related to the ageing process and other diseases.

\section{CONCLUSION}

The onset of trauma $<21$ days, GCS score $<13$, the thickness of hematoma $>15 \mathrm{~mm}$, and midline shift $>10 \mathrm{~mm}$ are risk factors for unfavourable outcomes in SDH patients after burr hole drainage. From the multivariate analysis test, it was found that GCS $<13$ was the most significant risk factor for unfavourable outcome in SDH patients after burr hole drainage.

\section{CONFLICT OF INTEREST}

There is no competing interest regarding the manuscript.

\section{ETHICS CONSIDERATION}

Ethics approval has been obtained from the Ethics Committee, Faculty of Medicine, Universitas Udayana, Sanglah General Hospital, prior to the study being conducted.

\section{FUNDING}

None.

\section{AUTHORS CONTRIBUTION}

All of the authors are equally contributed to the study from the conceptual framework, data gathering, data analysis, until reporting the results of study through publication.

\section{REFERENCES}

1. Wilberger JE Jr, Harris M, Diamond DL. Acute subdural hematoma: morbidity, mortality, and operative timing. J Neurosurg. 1991;74(2):212-218.

2. Lee JJ, Segar DJ, Morrison JF, Mangham WM, Lee S, Asaad WF. Subdural hematoma as a major determinant of short-term outcomes in traumatic brain injury. J Neurosurg. 2018;128(1):236-249.

3. Balser D, Farooq S, Mehmood T, Reyes M, Samadani U. Actual and projected incidence rates for chronic subdural hematomas in United States Veterans Administration and civilian populations. J Neurosurg. 2015;123(5):1209-1215.

4. Weigel R, Krauss JK, Schmiedek P. Concepts of neurosurgical management of chronic subdural haematoma: historical perspectives. Br J Neurosurg. 2004;18(1):8-18.

5. Weimer JM, Gordon E, Frontera JA. Predictors of Functional Outcome After Subdural Hematoma: A Prospective Study. Neurocrit Care. 2017;26(1):70-79.

6. Bokka S, Trivedi A. Histopathological study of the outer membrane of the dura mater in chronic sub dural hematoma: Its clinical and radiological correlation. Asian J Neurosurg. 2016;11(1):34-38.

7. Bin Zahid A, Balser D, Thomas R, Mahan MY, Hubbard ME, Samadani U. Increase in brain atrophy after subdural hematoma to rates greater than associated with dementia. J Neurosurg. 2018;129(6):1579-1587.

8. Karibe H, Hayashi T, Narisawa A, Kameyama M, Nakagawa A, Tominaga T. Clinical Characteristics and Outcome in Elderly Patients with Traumatic Brain Injury: For Establishment of Management Strategy. Neurol Med Chir (Tokyo). 2017;57(8):418-425. 
9. Syahrul S, Imran I, Fajri N. Clinical characteristics of traumatic brain injury patients in Dr. Zainoel Abidin Public Hospital Banda Aceh, Indonesia. Bali Medical Journal. 2020;9(1):194-200.

10. Edlmann E, Giorgi-Coll S, Whitfield PC, Carpenter KLH, Hutchinson PJ. Pathophysiology of chronic subdural haematoma: inflammation, angiogenesis and implications for pharmacotherapy. J Neuroinflammation. 2017;14(1):108

11. Adhiyaman V, Asghar M, Ganeshram KN, Bhowmick BK. Chronic subdural haematoma in the elderly. Postgrad Med J. 2002;78(916):71-75.

12. Gelabert-González M, Iglesias-Pais M, García-Allut A, Martínez-Rumbo R. Chronic subdural haematoma: surgical treatment and outcome in 1000 cases. Clin Neurol Neurosurg. 2005;107(3):223-229.

13. Abe Y, Maruyama K, Yokoya S, Noguchi A, Sato E, Nagane M, et al. Outcomes of chronic subdural hematoma with preexisting comorbidities causing disturbed consciousness. J Neurosurg. 2017;126(4):1042-1046.

14. Rovlias A, Theodoropoulos S, Papoutsakis D. Chronic subdural hematoma: Surgical management and outcome in 986 cases: A classification and regression tree approach. Surg Neurol Int. 2015;6:127.

15. Kim DH, Park ES, Kim MS, et al. Correlation between Head Trauma and Outcome of Chronic Subdural Hematoma. Korean J Neurotrauma. 2016;12(2):94-100.
16. Kim DI, Kim JH, Kang HI, Moon BG, Kim JS, Kim DR. Impact of Time Interval between Trauma Onset and Burr Hole Surgery on Recurrence of Late Subacute or Chronic Subdural Hematoma. J Korean Neurosurg Soc. 2016;59(5):498-504.

17. Wang YQ, Gu MC, Shi Q, Wang WP, Liu JY, Zhang ZD, et al. Chronic Subdural Hematoma with Hypodense on CT-Scan in the Elderly: Surgical Drainage or Conservative Treatment. 2016;7(3):1-9.

18. Yang AI, Balser DS, Mikheev A, et al. Cerebral atrophy is associated with development of chronic subdural haematoma. Brain Inj. 2012;26(13-14):1731-1736.

19. Kim TH, Park ES, Park JB, Kwon SC, Lyo IU, Sim HB, et al. Outcome and Prognostic Factors in Patients with Chronic Subdural Hematoma Classified According to the Initial Glasgow Coma Scale Score. The Nerve. 2017;3(1):25-31.

20. Amirjamshidi A, Abouzari M, Rashidi A. Glasgow Coma Scale on admission is correlated with postoperative Glasgow Outcome Scale in chronic subdural hematoma. J Clin Neurosci. 2007;14(12):1240-1241.

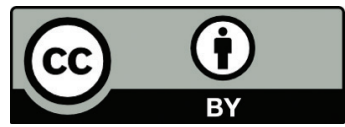

This work is licensed under a Creative Commons Attribution 